The enthusiasm of the Chinese for making results available to foreign scientists is only to be expected - after all, they have had some spectacular successes in earthquake prediction (as well as a notable failure) and have every right to be proud of their achievements. With regard to seismological data, the Chinese have followed an open policy; they report the data from their nuclear tests to the International Seismological Centre (the Soviet Union has only recently started this practice) and participate actively in the meetings of the UN Group of Scientific Experts where seismological methods of monitoring test-ban treaties are discussed.

The unique work on earthquake prediction, regional seismicity, deep seismic sounding and crustal structure in China is worthy of wide distribution. The two journals reviewed here are of a high standard and certainly help towards filling a gap in the Earth science literature. They should be welcomed - after all seismology is a global science, with researchers world-wide depending on the free exchange of data and ideas to tackle such outstanding problems as earthquake prediction. It remains to be seen whether recent events in China perturb the previously open approach to the exchange of scientific information; it would be most unfortunate if they did.

Peter D. Marshall is in the MOD(PE) Seismology Unit, Blacknest, Brimpton, Reading RG7 4RS, UK.

\section{Sixties style}

John B. Thornes

Geomorphology. Editor-in-chief M. Morisawa. Elsevier. 8/yr. Dfl. 2928.

IN ITS early days, at the latter part of the last century, geomorphology was rooted in both geology (in North America) and geography (in Europe). The geologists were mainly interested in what the subject could contribute to Earth's history at a time when they were less preoccupied with geochemistry and geophysics. The geographers saw it as the key element in understanding the contemporary landscape, and sought to find out how processes such as weathering, erosion and tectonic activity interacted with rocks to produce the landforms we now see.

Since the late 1950s the historical and mainly descriptive element and the process element have gradually moved further and further apart, each spawning its own specialist journals for historical (mainly Quaternary) studies and for investigations of Earth surface processes and landforms. The former has allied with sedimentary geochemistry and palaeobotany, the latter with hydrology, soil physics and chemistry, and hydraulics.

Geomorphologists therefore have a large number of publication outlets; not only are there the three main journals covering the field, but plenty of others dealing with geology, hydrology, geography, soil science and (more recently) environmental issues. So this newcomer has to find a place within a highly competitive environment.

The route the editor has taken is to reoccupy the ground lost in the 1960 s by concentrating on the application of contemporary processes to solving problems with a historical dimension. There is also a reassertion of the importance of geology as an underpinning of most if not all geomorphological problems. The methodology has so far emphasized the empirical and descriptive rather than the analytical, and the bridge with Quaternary research has been quickly and effectively reestablished. The journal has a North American provenance and market at a time when the main research and publication thrust had shifted to Europe and European journals.

For all these reasons Geomorphology has a good chance of success. Too much of intellectual value has been discarded in the past two decades, leaving a disaffected group without a focus of publication. The other main journals, Catena, Earth

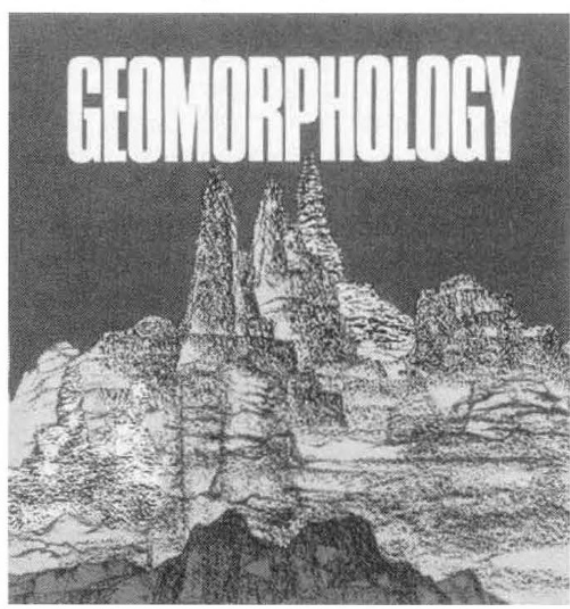

Surface Processes and Landforms and Zeitschrift für Geomorphologie, each excellent in its own area, failed to attract this wider spectrum of interest.

The main danger, already evident in some of the papers, is that in addition to picking up the abandoned intellectual issues of the 1960s, Geomorphology may pick up the abandoned methodologies of the same period. If Morisawa can avoid this pitfall, the journal seems likely to attract a wide readership.

John B. Thornes is in the Department of Geography, University of Bristol, University Road, Bristol BS8 1SS, UK.

\section{Entomological action}

\section{John Brady}

Journal of Insect Behavior. Co-editors William J. Bell and Thomas L. Payne. Plenum. 6/yr. United States \$135, elsewhere $\$ 160$ (institutional); US $\$ 42.50$, elsewhere $\$ 50$ (personal).

Hitherto there has not been a journal devoted to insect behaviour. On the other hand, there have been others that for years have contained the bulk of the literature on the subject: notably the Journal of Insect Physiology, Physiological Entomology and Comparative Physiology. These are all of European provenance, however, and are concerned more with the mechanisms of behaviour - what the Germans significantly call Verhaltensphysiologie than with its description.

The Journal of Insect Behavior, by contrast, is intended to cover almost everything behavioural that can be examined in terrestrial arthropods, including descriptive studies, social behaviour, orientation, learning, behavioural modelling and all that which is nowadays called 'behavioural ecology'. It is also an American publication, with half of its editorial board from US institutes and most of its papers from there, too. So, if its expansion from four to six issues a year from its second volume is any indicator, it is evidently fulfilling a need.

Thus far, the quality of its contents have been generally good, although the occasional "Short Communication" (always a doubtful scientific bet) has been distinctly weak. Happily, the bulk of its coverage has not yet seriously duplicated its older rivals' interests in behavioural physiology. For those mainly concerned with that area, it is to be hoped that this lack of overlap will continue.

At the end of the day, however, it is an editor's job to do more than just publish good science: he also has a duty to maintain the communication of science at a reasonable level of literacy. Without this check and control, scientific communication can degrade into the unreadable, telegraphic and ambiguous. Sadly, this task seems to be taking an increasingly secondary role in scientific editing. Perhaps that is because of the pressure to get out more and more papers faster and faster; or is it just that no one cares any more? In this respect, the literacy of the editors' introductory statement to Vol. 1 of the Journal of Insect Behavior is not particularly encouraging.

John Brady is in the Department of Pure and Applied Biology, Imperial College at Silwood Park, Ascot SL5 7PY, UK. 